\title{
Load-bearing capacity of indirect inlay-retained fixed dental prostheses made of particulate filler composite alone or reinforced with E-glass fibers impregnated with various monomers
}

Özcan, Mutlu ; Koekoek, Winand ; Pekkan, Gurel

\begin{abstract}
The load-bearing capacity and failure types of indirect inlay-retained fixed dental prostheses (FDP), made of particulate filler composite (PFC) (Estenia) alone or reinforced with E-glass fibers impregnated with various monomers were evaluated. Indirect inlay-retained FDPs were made between first premolars and first molars $(\mathrm{N}=30,10$ /per group). The inlay parts of the specimens were silica coated and silanized and the specimens were cemented with dual-polymerized resin cement under ultrasonic vibrations. The experimental groups were as follows: Group 1: FRC1 (BR-100, UTMA) + PFC; Group 2: FRC2 (everStick CB, Bis-GMA/PMMA) + PFC; Group 3: $\mathrm{PFC}$ only. The specimens were kept in distilled water at $37{ }^{\circ} \mathrm{C}$ for one month and then subjected to fracture strength test. No significant difference was found between the Group 1 and Group 2 FDPs (1357 $\pm 301 \mathrm{~N}$ and $1213 \pm 316 \mathrm{~N}$, respectively) (p>0.05) (ANOVA). Group $3(856 \pm 299 \mathrm{~N})$ showed significantly lower results than those of FRC reinforced groups $(\mathrm{p}<0.05)$. Failure analyses revealed no debonding of any of the FDPs from the inlay cavities. FDPs made of PFC only showed mainly catastrophic fracture of the pontic. In the FRC reinforced groups, predominantly delamination of the veneering was observed. The use of silica coating and silanization in combination with the dual-polymerized resin cement used; under ultrasonic cementation procedure provided sufficient adhesion to withstand static loading forces at the cementation interface, since the failures were predominantly delamination of the veneering in the FRC reinforced groups.
\end{abstract}

DOI: https://doi.org/10.1016/j.jmbbm.2012.02.023

Posted at the Zurich Open Repository and Archive, University of Zurich ZORA URL: https://doi.org/10.5167/uzh-75524

Journal Article

Accepted Version

Originally published at:

Özcan, Mutlu; Koekoek, Winand; Pekkan, Gurel (2012). Load-bearing capacity of indirect inlay-retained fixed dental prostheses made of particulate filler composite alone or reinforced with E-glass fibers impregnated with various monomers. Journal of the Mechanical Behavior of Biomedical Materials, 12:160-167.

DOI: https://doi.org/10.1016/j.jmbbm.2012.02.023 
Load-bearing capacity of indirect inlay-retained fixed dental prostheses made of particulate filler composite alone or reinforced with E-glass fibers impregnated with various monomers

Mutlu ÖZCAN ${ }^{1}$, Winand KOEKOEK ${ }^{2}$, Gurel PEKKAN ${ }^{3}$

${ }^{1}$ University of Zürich, Dental Materials Unit, Center for Dental and Oral Medicine, Clinic for Fixed and Removable Prosthodontics and Dental Materials Science, Plattenstrasse 11, CH-8032 Zürich, Switzerland

${ }^{2}$ Private practice, Groningen, Netherlands

${ }^{3}$ Dumlupinar University, Faculty of Dentistry, Tavsanli Yolu 10. Km, 43270 Kutahya, Turkey

Short title: Load-bearing capacity of inlay-retained fixed dental prostheses

Corresponding author details:

Prof. Dr. med. dent. Mutlu Özcan

University of Zürich, Dental Materials Unit, Center for Dental and Oral Medicine Clinic for Fixed and Removable Prosthodontics and Dental Materials Science, Plattenstrasse 11, CH-8032, Zürich, Switzerland.

Tel: $+41-44-6345600$

Fax: +41-44-63 44305

E-mail: mutluozcan@hotmail.com 


\section{ABSTRACT}

Objectives: The load-bearing capacity and failure types of indirect inlay-retained fixed dental prostheses (FDP), made of particulate filler composite (PFC) (Estenia) alone or reinforced with E-glass fibers impregnated with various monomers were evaluated.

Materials and Methods: Indirect inlay-retained FDPs were made between first premolars and first molars ( $\mathrm{N}=30,10 /$ per group). The inlay parts of the specimens were silica coated and silanized and the specimens were cemented with dualpolymerized resin cement under ultrasonic vibrations. The experimental groups were as follows: Group 1: FRC1 (BR-100, UTMA) + PFC; Group 2: FRC2 (everStick C\&B, Bis-GMA/PMMA) + PFC; Group 3: PFC only. The specimens were kept in distilled water at $37^{\circ} \mathrm{C}$ for one month and then subjected to fracture strength test.

Results: No significant difference was found between the Group 1 and Group 2 FDPs $(1357 \pm 301 \mathrm{~N}$ and $1213 \pm 316 \mathrm{~N}$, respectively) ( $p>0.05)$ (ANOVA). Group 3 (856 $\pm 299 \mathrm{~N}$ ) showed significantly lower results than those of FRC reinforced groups $(p<0.05)$. Failure analyses revealed no debonding of any of the FDPs from the inlay cavities. FDPs made of PFC only showed mainly catastrophic fracture of the pontic. In the FRC reinforced groups, predominantly delamination of the veneering was observed.

Conclusions: The load-bearing capacity of the indirect inlay-retained FPDs made of PFC reinforced with both BR-100 and everStick C\&B revealed statistically similar results that were significantly higher than PFC alone. The use of silica coating and silanization in combination with the dual-polymerized resin cement used; under ultrasonic cementation procedure provides sufficient adhesion to withstand static loading forces at the cementation interface, since the failures were predominantly 
delamination of the veneering in the FRC reinforced groups.

Keywords: Fracture strength, inlay retained fixed dental prostheses, fiber reinforced composite 


\section{Introduction}

Due to the increase in conscious in minimal invasive approach in dentistry, new materials are being introduced in the dental market that allow for minimal tooth preparations and restoration of lost dental tissues (Wyatt, 2007). Resin-bonded fixed dental prostheses (FPDs) with metal or ceramic frameworks are considered as minimal invasive treatment modalities (Creugers et al., 1997; Kern and Sasse 2011; Kerschbaum et al., 1996; Kumbuloglu et al., 2008; Wyatt, 2007). Such restorations serve as a practical and conservative approach in dentistry. However, low bond strength of metal and ceramic FDPs to the tooth tissues remains to be the clinical problem leading to frequent debondings (Creugers et al., 1997; Kern and Sasse 2011; Kerschbaum et al., 1996). As a consequence of different modulus of elasticity of the different materials and the repeated stresses, the adhesive joint was often reported to be the main cause of failure (Behr et al., 2002; Creugers et al., 1997; Kerschbaum et al., 1996; Kumbuloglu et al., 2008). One alternative to metal or ceramic resin-bonded FDPs is fiber reinforced composite (FRC) FDPs that require minimal preparation of the tooth tissues, especially when compared with their conventional metal and ceramic counterparts (Özcan et al., 2005a; Ries et al., 2006; Waki et al., 2006).

Conventional full-coverage or implant-retained FPDs could be considered invasive, time-consuming, and expensive (Keulemans et al., 2009). For patients who normally could not be treated with fixed appliances because of these factors, an FRC FDP can be offered as a single tooth replacement at much lower costs. This kind of treatment covers a whole new group of indications in dentistry (Vallittu, 1999; Vallittu and Sevelius, 2000). One other reason to use FRCs in practice is to avoid abrasion in the antagonist enamel caused by metal-ceramic restorations (Kramer et 
al., 2006). Resin composite materials are less abrasive and traumatic than ceramics. Although, there is limited information on the longevity and clinical behavior of FRC FDPs, available clinical studies showed that FRC FDPs are able to function acceptable with reported five year-survival rates ranging between 73\% (Göhring and Roos, 2005) and 78\% (van Heumen et al., 2010).

FRC FDPs are composed of two types of resin composite materials namely, the fiber composite to build the framework, and hybrid or microfilled particulate filler composites (PFC) to create the external veneer surface (Kumbuloglu et al., 2008). Among many other FRC materials, glass fibers are easily silanized and preimpregnated in order to supply good attachment of the PFC. Pre-impregnation can be achieved with monomers, polymers or a combination of two or more of methacrylate monomers. Pre-impregnation is often performed using various monomers, such as bisphenol glycidylmethacrylate (bis-GMA), urethane dimethacrylate (UDMA), urethane tetramethacrylate (UTMA), polymethylmethacrylate (PMMA) or triethylene glycidylmethacrylate (TEGDMA) (Kumbuloglu et al., 2008; Lastumäki et al., 2003; Minesaki, 2002; Pensler et al., 1997; Vallittu, 1999). Effective impregnation allows the matrix to come into contact with the surface of each fiber (Vallittu, 1995). Good impregnation of fibers with the surrounding matrix is important because fiber reinforcement is only successful when the loading force could be transferred from the matrix to the fiber (Behr et al., 2000; Vallittu, 1996). Impregnation with a monomer only causes high polymerization shrinkage (Vallittu, 1996), that may impair the mechanical properties of the FRC and the adhesion of the PFC. Since a mixture of polymers and monomers such as bisGMA/PMMA do not seem to suffer from this phenomenon (Vallittu, 1996), they may be anticipated to deliver more favorable results. One problem associated with using 
the polymer-monomer mixture in direct chairside pre-impregnation is the high viscosity that makes handling difficult (Vallittu, 1996). In order to overcome this problem, pre-impregnated FRC systems are developed, meaning that the FRC bundle can be applied as such when taken out of the package (Miettinen et al., 1998; Vallittu, 1998, 1994). Monomers such as UTMA and bis-GMA/PMMA, changes handling properties and cross-linking, thereby, increase the adhesive strength of the FRC to the PFC (Kumbuloglu et al., 2008). On the other hand, the development and improvement of PFCs has been a great challenge for the manufacturers. Typically, filler particles in different sizes and volumes added to the resin matrix. One of the latest developments in this field incorporated a mixture of large quantity of ultrafine fillers (particle size of $0.02 \mu \mathrm{m}$ ) with micro-filled (particle size of $2 \mu \mathrm{m}$ ) in the resin matrix, the so-called hybrid ceramic. With the use of such materials, one can get a high volume percentage of fillers into the resin matrix.

FRC FDPs can be manufactured either directly in the mouth or indirectly. The most important reasons for preferring indirect FDPs to the direct ones are avoiding moisture during cementation that has negative effect on polymerization, and initial shrinkage where the latter outside the mouth gives less stress on the abutments in comparison to direct FDPs (Miettinen et al., 1998).

The objectives of this present study were to compare 1) the load-bearing capacity of indirect inlay-retained FDPs reinforced with two types of E-glass FRCs, pre-impregnated with either UTMA or bis-GMA/PMMA monomers versus non-fiber reinforced indirect inlay-retained PFC FDPs, and b) to determine the failure types and location after the fracture test. The tested hypotheses were that bis-GMA/PMMA impregnated FRC FDPs would stand higher loads than UTMA impregnated ones and that FRC FDPs would be more stable than PFC FDPs. 


\section{Materials and Methods}

\subsection{Specimen preparation}

Recently extracted sound human first premolars $(n=30)$ and first molars $(n=30)$ were randomly divided into 3 groups. The teeth were stored in distilled water with $0.1 \%$ thymol solution at $4{ }^{\circ} \mathrm{C}$ temperature until the experiments. They were embedded in auto-polymerized PMMA (Vertex, Zeist, Netherlands) to create a situation as if a second premolar was missing. Using a denture tooth with a mesiodistal length of $7 \mathrm{~mm}$, a standard distance of $7 \mathrm{~mm}$ was kept between the abutment teeth (Fig. 1). On the mesial side of the first premolar and distal side of the first molar, standard Class II box preparations were made initially using conventional fine diamond inlay burs (model number 011, Cerinlay; Intensiv, Grancia, Switzerland) with a high-speed handpiece (KaVo K9, handpiece type 950; KaVo, Biberach, Germany) utilizing water spray. A new set of burs was used after every 10 preparations. Boxes with margins in enamel with standard buccolingual (BL), mesiodistal (MD), and cervico-occlusal (CO) dimensions, at least $1 \mathrm{~mm}$ above the cemento-enamel junction, were prepared using small ultrasonic tips (SONICSYS approx, micro torpedo; KaVo) designed for molars (BL: 2.9 mm, MD: 3.8 mm, CO: $3.6 \mathrm{~mm}$ ) and small ultrasonic tips for the premolars (BL: $2.6 \mathrm{~mm}, \mathrm{MD}: 2.7 \mathrm{~mm}, \mathrm{CO}$ : $2.9 \mathrm{~mm}$ ). The linear oscillation speed was $6.5 \mathrm{kHz}$. Subsequently, the dimensions of the boxes were measured at $\mathrm{BL}, \mathrm{MD}$, and $\mathrm{CO}$ directions with a digital micrometer (accurate to 0.005 microns) (Mitutoyo Ltd, Andover, UK). The specimens with the prepared teeth were randomly divided into 3 groups to receive the indirect inlayretained FDPs. The specimens were kept in distilled water at all times besides making impression and cementation. 


\subsection{FDP production}

After the initial impression of these 30 specimens with vinyl polysiloxane putty (Express $^{\mathrm{TM}}$ STD, 3M ESPE AG, Seefeld, Germany), space was created especially at the box area for the fine impression material, vinyl polysiloxane, (Provil, Medium fast set, Heraeus Kulzer GmbH \& Co. KG, Hanau, Germany). Impressions were poured in Type IV dental stone (Begostone, Bego, Bremen, Germany). The FDPs were manufactured on the stone casts. The stone casts were initially isolated with an insulation liquid (CR SEP III, Estenia, Kuraray Medical Inc., Tokyo, Japan). The inlay-retained FRC FDPs in the first group $(n=10)$ were made by using FRCs preimpregnated with UTMA (BR-100, Kuraray Medical Inc.) and micro-filled hybrid PFC (Estenia, Kuraray Medical Inc.). The second group $(n=10)$ was restored using Eglass fibers (everStick C\&B, Stick Tech Ltd, Turku, Finland) pre-impregnated with bis-GMA/PMMA and PFC, Estenia. The third group acted as the control group where the FDPs were not reinforced with FRCs but made out of PFC, Estenia, only. The brands, manufacturers and chemical compositions of the materials used in this study are listed in Table 1.

Firstly, the boxes were sealed with an adhesive resin (VisioBond, 3M ESPE AG Seefeld, Germany) and photo-polymerized for 20 seconds. The light output was above $600 \mathrm{~mW} / \mathrm{cm}^{2}$ at all polymerization procedures. Then a short metal matrix (5 $\mathrm{mm}$ ) (AESCULAP AG, Tuttlingen, Germany) was placed between the abutments and approximately $2 \mathrm{~mm}$ thickness of PFC was applied at the cervical pontic area. After polymerizing this PFC layer, little amount of flowable composite (Stick Flow, Stick Tech Ltd) was applied in the boxes. Previously measured and cut one FRC bundle was placed in the bed of the flowable resin in the boxes using the "curved" method described by Waki et al. (2006). After photo-polymerization for 20 seconds 
per box and in the pontic area, Class II restorations were made on the abutment teeth. Subsequently, PFC was applied incrementally to build-up the pontic with the help of a silicon mold to achieve standard dimensions. The occlusal pattern was formed using the $6 \mathrm{~mm}$ diameter steel ball that acted as the antagonist anatomy (Özcan et al., 2005a). The control group was built up in the same manner out of PFC only.

Inlay-retained FDPs were fully polymerized in a photo and heat polymerization device (Shining 2000, La Tecnomedica srl, Voghera, Italy) for 15 minutes at $110^{\circ} \mathrm{C}$. The dimensions of the FDPs were measured, adjusted when necessary and finally finished and polished with coarse, medium, fine, and ultrafine finishing disks (Sof-Lex, 3M ESPE).

\subsection{Adhesive cementation}

The cementation surfaces of the inlays were conditioned using $30 \mu \mathrm{m}$ alumina particles coated with silica (CoJet Sand, 3M ESPE AG, Seefeld, Germany) with a chair side air-abrasion device (Dento-Prep ${ }^{\mathrm{TM}}$, Rønvig, Denmark) in circling movements for 5 seconds until the surface appeared visually matte (Fig. 2). Then, a silane coupling agent (ESPE-Sil, 3M ESPE AG) was applied to the cementation surfaces and waited for its reaction for 5 minutes. The silanized surfaces received a thin layer of adhesive resin (VisioBond, 3M ESPE AG) and air-thinned.

After etching and rinsing the enamel and dentin with $38 \%$ phosphoric acid (TopDent, DAB Dental, Göteborg, Sweden) for 20 seconds, primer (Quadrant primer, Cavex, Haarlem, Netherlands), and subsequently adhesive resin (Quadrant sealer, Cavex) was applied on the dentin according to manufacturer's instructions. Inlay-retained FDPs were adhesively cemented using dual-polymerized resin 
cement (Panavia F 2.0, Kuraray Medical Inc.) under oscillating vibrations (Amdent AB, Nynashamn, Sweden) for 10 seconds (Fig. 3). After removing the excess cement, the FDP was photo-polymerized for 40 seconds at each site. Then oxygen inhibition gel (Oxyguard, Kuraray Medical Inc.) was applied at the FDP inlay margins and photo-polymerized for another 40 seconds at each site.

\subsection{Testing and failure analysis}

The specimens were stored in distilled water for 1 month at $37^{\circ} \mathrm{C}$ until the fracture tests. The specimens were loaded from the occlusal direction to the central fossa with a steel contact ball, $6 \mathrm{~mm}$ in diameter that started moving from a distance of $2 \mathrm{~mm}$ from the occlusal surface at a crosshead speed of $1 \mathrm{~mm} / \mathrm{min}$ (Zwick ROELL Z2.5 MA 18-1-3/7, Zwick, Ulm, Germany). A sheet of tin foil (0.4 mm) was inserted between the steel ball and the pontic in order to avoid local peaks and sliding of the load cell (Kumbuloglu et al., 2008; Özcan et al., 2005a). The load was applied until the fracture load decreased by $10 \%$ of the maximum load (Fmax) (Kumbuloglu et al., 2008; Özcan et al., 2005a).

After fracture tests, two operators analyzed the failure types were under stereomicroscope (Olympus America Inc., NY, USA) at a magnification of x50 and classified the failure types in four groups as follows: Type 1: Cohesive fracture in the veneering resin without fiber exposure at either lingual or buccal site; Type 2: Cohesive fracture in the veneering resin without fiber exposure at both lingual and buccal site; Type 3: Cohesive veneering resin fracture including both lingual and buccal sites with fiber exposure; Type 4: Catastrophic pontic fracture where the inlay parts remained intact but the pontic itself splitted and Type 5: Small crack lines in the veneering resin with no obvious fracture of the pontic. 


\subsection{Statistical analysis}

Statistical analysis was performed using SPSS 11.0 software for Windows (SPSS Inc., Chicago, IL, USA). Fracture strength data (N) were submitted to oneway analysis of variance (1-way ANOVA) and Tukey-Kramer post-hoc tests to determine the significant differences between groups. $P$ values less than 0.05 were considered to be statistically significant in all tests.

\section{Results}

No significant difference was found between the mean fracture strength of inlay-retained FRC FDPs constructed using either UTMA $(1357 \pm 301 \mathrm{~N})$ or bisGMA/PMMA (1213 $\pm 316 \mathrm{~N})$ impregnated E-glass FRCs $(p>0.05)$ (ANOVA) (Fig. 4). Inlay-retained FDP group made of PFC only demonstrated mean fracture strength value with $856 \pm 299 \mathrm{~N}$, being significantly lower than those of fiber reinforced groups ( $p=0.004$ and $p=0.04$ for BR-100 and everStick C\&B, respectively).

Failure analyses revealed no debonding of any of the FDPs from the cavities. Inlay-retained FDPs made of PFC only showed mainly (6 out of 10) catastrophic pontic fracture where the inlay parts remained intact but the pontic itself splitted (Type 4) followed by Type 1 failure (4 out of 10) (Fig. 5). In the FRC reinforced groups cohesive fractures in the veneering resin without fiber exposure at both lingual and buccal sites (Type 2) were more commonly observed. The incidence and failure types per experimental group are demonstrated in Table 2.

\section{Discussion}

The results of this study indicated no significant difference between the loadbearing capacities of the inlay-retained indirect FRC FDPs. Therefore, the 
hypothesis that bis-GMA/PMMA impregnated FRC FDPs would stand higher loads than UTMA impregnated ones cannot be accepted. Since the inlay-retained FDPs made of only PFC delivered significantly lower results than those of other groups, the second hypothesis was accepted.

During clinical function, dental restorations are subjected to biting and chewing forces. The maximum bite forces during mastication have been investigated in many studies (Behr et al., 2002; Özcan et al., 2005a; Phillips, 1991; Rosentritt et al., 2000; Vallittu and Könönen, 2000). Different testing methods and the difficulty in measuring masticatory forces result in a wide range of force values. Stress applied on a restoration during mastication may range between $441-981 \mathrm{~N}, 245-491 \mathrm{~N}, 147-$ $368 \mathrm{~N}$, and 98-270 $\mathrm{N}$ in the molar, premolar, canine, and incisor regions, respectively (Phillips, 1991; Rosentritt et al., 2000; Vallittu and Könönen, 2000). According to some authors, a restoration should be able to withstand stress to approximately $500 \mathrm{~N}$ in the premolar region and $500 \mathrm{~N}$ to $900 \mathrm{~N}$ in the molar region (Behr et al., 2002; Özcan et al., 2005a). On the other hand, DIN standard stated that FDPs should withstand occlusal forces of more than $1000 \mathrm{~N}$ in a static fracture resistance test (Zhang and Matinlinna, 2011). The results of this study exhibited mean fracture strength values that were higher than $1200 \mathrm{~N}$ for the inlay-retained FRC FDPs. They can therefore be considered strong enough for clinical applications. The non-fiber reinforced group showed mean fracture strength of about $850 \mathrm{~N}$, which is below the recommended $1000 \mathrm{~N}$.

In-vitro fracture strength measurements involve many factors to take into consideration. Masticatory forces are not only axial as applied in such test methods. Thus a direct comparison between in-vivo an in-vitro chewing force measurement is difficult. Moreover, the morphology of the pontic may also affect the fracture strength 
(Özcan et al., 2005a). Recent studies presented significant differences between different pontic forms (Chen et al., 2011; Keulemans et al., 2009). In this study, the steel ball form was used to avoid any interference of the cusp height that could affect the results. Cusp morphology and its affect on the failure types deserve future research.

Furthermore, inter-abutment distance varied between 7 to $15 \mathrm{~mm}$ in different studies (Keulemans et al., 2009; Mehl et al., 2010; Nakamura et al., 2003; Shah et al., 2009; Song et al., 2003; Waki et al., 2006). In a previous study, it was reported that the fracture strength of inlay-retained FDPs reinforced with FRC was reduced by about 25 to $35 \%$ when the inter-abutment distance was increased from 7 to $11 \mathrm{~mm}$ (Song et al., 2003). All-ceramic inlay-retained FDPs are reported to have higher fracture strength values than their FRC reinforced counterparts. For zirconia inlayretained FDPs mean fracture strength was reported to be $1248 \pm 263 \mathrm{~N}$ when interabutment distance was $10 \mathrm{~mm}$ (Kilicarslan et al., 2004). Although, it is difficult to make a strict comparison because of the experimental conditions, the mean fracture strength values (BR-100+Estenia: 1357 $\pm 301 \mathrm{~N}$ and everStick C\&B+Estenia: $1213 \pm 316 \mathrm{~N}$ ) in this study were almost comparable with that of all-ceramic inlayretained FDPs in the aforementioned study. This high fracture strength values may be attributed to shorter inter-abutment distance in this study compared to that of the other studies (Behr et al., 2000; Waki et al., 2006). It was previously found that there was no significant difference among the fracture strength values of 4 different direct surface-retained FRCs (everStick C\&B, BR-100, Interling, and Ribbond) FDPs fabricated using a hybrid resin composite (Clearfil Photo Posterior) (Kumbuloglu et al., 2008). In that study, the FRC FDPs were constructed directly without any preparations on the palatal surfaces of the anterior abutment teeth whereas in this 
study the FRC FDPs were made indirectly. The results of this study are considerably lower even with the same FRC materials. This could be either due to better adhesion of the resin composite applied directly or the favorable forces in the anterior region. The authors stated that flexural strength of FRC restorations might be improved with the use of new polymer formulations with high filler particle distribution (Kumbuloglu et al., 2008).

Estenia is a highly filled UTMA based PFC. In this study, the results without fiber reinforcement was above the results reported earlier (Nakamura et al., 2003), where fiber reinforcement was used. This implies the importance of choosing a strong PFC in combination with the FRCs. Although, Estenia with $92 \%$ filler content was used as PFC material in this study, the fracture strength values were not as high as in a previous study (Kumbuloglu et al., 2008). In accordance with this, there was no significant difference between the fracture strength values of FRC FDPs in current study. Test conditions and water storage may have affected the strength values. It is known that the water storage may result in hydrolytic degradation between polymeric and non-polymeric interfaces (Shah et al., 2009). Non-fiber reinforced Estenia alone exhibited mean fracture strength value of $856 \pm 299 \mathrm{~N}$ that was relatively comparable with masticatory forces reported for the posterior area (Behr et al., 2002; Özcan et al., 2005a). Nevertheless, under the conditions of the oral environment, cyclic fatigue loading caused by mastication can considerably weaken the fracture resistance of dental restorations (Mehl et al., 2010). The endurance limit for fatigue cycling that can be applied to dental ceramics is approximately $50 \%$ of the maximal fracture strength (Geis-Gerstorfer and Feassler, 1999). Keulemans et al. (2010) reported that dynamic failure loads were significantly 
lower than static failure loads of PFC but not that of FRC. Further studies are needed to test the PFC and FRC FDPs in dynamic loading conditions.

Resin composites containing four-functional urethane methacrylate present both hardness and fracture toughness greater than those of two-functional urethane methacrylate (Yamaga et al., 1995). On the other hand, PMMA matrix is highly viscous compared to the dimethacrylate systems improving both the handling properties and bonding properties of the FRC after its polymerization (Dyer et al., 2005; Lastumäki et al., 2003; Tezvergil et al., 2005). In this current study, the mean fracture strength of both UTMA and bis-GMA/PMMA reinforced fibers did not differ significantly. There seems to be a slightly higher trend for BR-100 that contains Eglass and UTMA, but it needs to be verified on a larger sample size in future studies. The necessity of further reinforcement of FRC and PFC material combinations should be questioned in clinical studies.

In in-vitro studies not only the fracture strength values but also the failure types deliver important information. In both FRC groups, predominantly veneering resin fracture was experienced, but the fibers themselves remained intact. As it was expected, the failure types in non-fiber reinforced group were mainly catastrophic failures (Type 4). The failure analysis indicated that there are actually two types of failures, namely repairable and non-repairable fractures. With the use of FRCs, fracture was experienced cohesively within the veneering resin or at the fiber-resin interface where clinician has still the chance to repair the failed inlay-retained FRC FDP. The Type 1 and 2 failures experienced in FRC reinforced groups and Type 4 in inlay-retained PFC FDPs underlines the importance and necessity of strong composite reinforcement. Perhaps fracture type classification in future studies should be made on clinical reparability. 
One important observation of this study was the incidence of the failure types being most frequently at the buccal and/or lingual side of the FRC FDPs. These observations were made also at lower fracture values. This could be due to variations in force distribution from the occlusal side. Although utmost attention was paid to use the steel load cell as the antagonist tooth anatomy, small variations might have happened during placement of the steel load cell. Although pontic dimensions, box dimensions, polymerization, finishing and polishing were performed under standard conditions, small variations in contact of the steel load cell and the occlusal table may change the direction of the forces. The results of the research revealed that in deep occlusal anatomies, the steel load cell creates lateral forces leading to lingual or buccal fracture of the veneering resin (Özcan et al., 2005a). In rather shallow occlusal forms as the case here, the occlusal forces could be expected to distribute more evenly. Additionally, there seemed to be higher loading resistance of the FDPs in the cases of Type 3 and Type 5 failures in comparison to other specimens that presented different failure types. Future studies should associate failure types with the magnitude of load on larger sample size.

One interesting finding of this study was that no failures were observed at the cementation joint. Indirect FRC FDPs are processed in heat and photo induced polymerization devices where no reactive monomers are expected to react with the cement. For this reason, in previous studies the weakest point of such restorations was reported as the cementation interface (Behr et al., 2002; Dyer et al., 2005). In this study, the cementation surfaces of the FDPs were conditioned with silica coating, silanized and treated with adhesive resin prior to cementation. The findings of this study with no failures in the form of debondings agree with the strengthening mechanism of this conditioning method coupled with good adhesion of the cement to 
dental tissues as described earlier (Özcan et al., 2005b). Furthermore, the use of ultrasonic cementation might have created even distribution of the cement layer and thereby good polymerization that all contributed to strong cementation interface to resist the occlusal force during testing.

Many factors affect the durability of FRC restorations. These include the properties of the fibers, resin matrix, impregnation of the fibers with the resin, adhesion of fibers to the matrix, the quantity of fibers, direction, orientation, location, construction, distribution, and position of the fibers (Minesaki, 2002; Pensler et al., 1997). Nevertheless, a good pre-impregnation of the FRC would lead to good attachment of the veneering composite and thereby stronger FRC FDPs.

One limitation of this study is the non-inclusion of an artificial aging process, such as mechanical loading that would have negative effect on fracture strength. Therefore, the results may be valid for possible early clinical failures. Another limitation is not simulating the physiological tooth movement. Rigidity of the used test set-up could have influenced the load-bearing capacities in a negative way (Fischer et al., 2004). Non-rigidly mounted abutments with an elastic modulus close to that of natural teeth are capable of giving a more realistic representation of the oral situation. However, there is no consensus to date whether or not to simulate the periodontal conditions with silicone based materials. Furthermore, comparisons among materials in this study were made based on strength values at final failure. However, it must be emphasized that initial fracture strengths of FRCs and PFCs might show variations (Özcan et al., 2005a; Kumbuloglu et al., 2008).

\section{Conclusions}

From this in vitro study, the following conclusions could be drawn: 
1- Both UTMA and bis-GMA/PMMA pre-impregnated E-glass FRC reinforced indirect inlay-retained FDPs presented high fracture strength values in conjunction with highly filled particulate filler composite (Estenia) $(>1.200 \mathrm{~N})$, being not statistically significant from one another $(p>0.05)$.

2- Both FRC reinforced groups showed significantly higher results than that of the group made of PFC only.

3- After the fracture test, while in the non-FRC reinforced group, mainly catastrophic failure of the pontic was observed; in the FRC reinforced groups predominantly delamination of the veneering resin was experienced.

4- Since no debonding of the inlays were observed, it can be stated that the use of silica coating and silanization in combination with the dual-polymerized resin cement used, under ultrasonic cementation procedure provides sufficient adhesion to withstand static loading forces at the cementation interface. 


\section{Acknowledgements}

The authors acknowledge Kuraray $\mathrm{GmbH}$, Tokyo, Japan for providing BR-100 fibers and Estenia particulate filled composite, and StickTech Ltd., Turku, Finland for providing everStick C\&B fibers.

\section{Conflict of interest}

The authors declare no conflicts of interest. 


\section{References}

Behr, M., Rosentritt, M., Lang, R., Handel, G., 2000. Flexure properties of fiberreinforced-composite using a vacuum/ presurre or a manual adaptation manufacturing process. J. Dent. 28, 509-514.

Behr, M., Rosentritt, M., Ledwinsky, E., Handel, G., 2002. Fracture resistance and marginal adaptation of conventionally cemented fiber-reinforced composite threeunit FPDs. Int. J. .Prosthodont. 15, 467-472.

Chen, Y., Li, H., Fok, A., 2011. In vitro validation of a shape-optimized fiberreinforced dental bridge. Dent. Mater. 27, 1229-1237.

Creugers, N.H., De Kanter, R.J., van't Hof, M.A., 1997. Long-term survival rate from a clinical trial on resin-bonded bridges. J. Dent. 25, 239-242.

Dyer, S.R., Sorensen, J.A., Lassila, L.V., Vallittu, P.K., 2005. Damage mechanics and load failure of fiber-reinforced composite fixed partial dentures. Dent. Mater. 21, 1104-1110.

Fischer, H., Weber, M., Eck, M., Erdrich, A., Marx, R., 2004. Finite element and experimental analyses of polymer-based dental bridges reinforced by ceramic bars. J. Biomech. 37, 289-294.

Geis-Gerstorfer, J., Faessler, P., 1999. Evaluation of the endurance limit for fatigue cycling of dental ceramics. Dtsch. Zahnarztl. Z. 54, 692-694.

Göhring, T.N., Roos, M., 2005. Inlay-fixed partial dentures adhesively retained and reinforced by glass fibers: clinical and scanning electron microscopy analysis after five years. Eur. J. Oral. Sci. 113, 60-69.

Kern, M., Sasse, M., 2011. Ten-year Survival of Anterior All-ceramic Resin-bonded Fixed Dental Prostheses. J. Adhes. Dent. 13, 407-410.

Kerschbaum, T., Haastert, B., Marinello, C.P., 1996. Risk of debonding in three-unit 
resin-bonded fixed partial dentures. J. Prosthet. Dent. 75, 248-53.

Keulemans, F., Lassila, L.V., Garoushi, S., Vallittu, P.K., Kleverlaan, C.J., Feilzer, A.J., 2009. The influence of framework design on the load-bearing capacity of laboratory-made inlay-retained fibre-reinforced composite fixed dental prostheses. J. Biomech. 42, 844-849.

Keulemans F, Van Dalen A, Kleverlaan CJ, Feilzer AJ. Static and dynamic failure load of fiber-reinforced composite and particulate filler composite cantilever resin-bonded fixed dental prostheses. J Adhes Dent 2010; 12: 207-214.

Kilicarslan, M.A., Kedici, P.S., Kucukesmen, H.C., Uludag, B.C., 2004. In vitro fracture resistance of posterior metal-ceramic and all-ceramic inlay-retained resinbonded fixed partial dentures. J. Prosthet. Dent. 92, 365-370.

Kramer, N., Kunzelmann, K.H., Taschner, M., Mehl, A., Garcia-Godoy, F., Frankenberger, R., 2006. Antagonist enamel wears more than ceramic inlays. J. Dent. Res. 85, 1097-1100.

Kumbuloglu, O., Ozcan, M., User, A., 2008. Fracture strength of direct surfaceretained fixed partial dentures: effect of fiber reinforcement versus the use of particulate filler composites only. Dent. Mater. J. 27, 195-202.

Lastumäki, T.M., Lassila, L.V.J., Vallittu, P.K., 2003. The semiinterpenetrating polymer network matrix of fiber-reinforced composite and its effect on the surface adhesive properties. J. Mater. Sci. Mater. Med. 14, 803-809.

Mehl, C., Ludwig, K., Steiner, M., Kern, M., 2010. Fracture strength of prefabricated all-ceramic posterior inlay-retained fixed dental prostheses. Dent. Mater. 26, 67-75. Miettinen, V.M., Narva, K.K., Vallittu, P.K., 1998. Water sorption, solubility and effect of post-curing of glass-fiber-reinforced polymers. Biomaterials 20, 1187-1194.

Minesaki, Y., 2002. In vitro wear of indirect composite restoratives. J. Prosthet. Dent. 
$88,431-436$.

Nakamura, T., Waki, T., Kinuta, S., Tanaka, H., 2003. Strength and elastic modulus of fiber-reinforced composites used for fabricating FPDs. Int. J. Prosthodont. 16, 549-553.

Özcan, M., Breuklander, M.H., Vallittu, P.K., 2005a. The effect of box preparation on the strength of glass fiber-reinforced composite inlay-retained fixed partial dentures. J. Prosthet. Dent. 93, 337-345.

Özcan, M., Alander, P., Vallittu, P.K., Huysmans, M.C., Kalk, W., 2005b. Effect of three surface conditioning methods to improve bond strength of particulate filler resin composites. J. Mater. Sci. Mater. Med. 16, 21-27.

Pensler, A.V., Bertolotti, R.L., Miller, D., 1997. Building laminate veneers and fixed bridges with polymer glass technology. Compend. Contin. Educ. Dent. 18, 712-720. Phillips, R.W., 1991. Physical Properties of Dental Materials. Rheology. Color. Thermal Properties In: Phillips, R.W., Skinner's Science of Dental Materials. Philadelphia: W.B. Saunders Company; p. 29-59.

Ries, S., Wolz, J., Richter, E.J., 2006. Effect of design of all-ceramic resin-bonded fixed partial dentures on clinical survival rate. Int. J. Periodontics Restorative Dent. 26, 143-149.

Rosentritt, M., Behr, M., Lang, R., Handel, G., 2000. Experimental design of FPD made of all-ceramic and fiber-reinforced composite. Dent. Mater. 6, 159-165.

Shah, M.B., Ferracane, J.L., Kruzic, J.J., 2009. R-curve behavior and toughening mechanisms of resin-based dental composites: effects of hydration and post-cure heat treatment. Dent. Mater. 25, 760-770.

Song, H.Y., Yi, Y.J., Cho, L.R., Park, D.Y., 2003. Effects of two preparation designs and pontic distance on bending and fracture strength of fiber-reinforced composite 
inlay fixed partial dentures. J. Prosthet. Dent. 90, 347-353.

Tezvergil, A., Lassila, L.V.J., Vallittu, P.K., 2005. The shear bond strength of bidirectional and random-oriented fiberreinforced composite to tooth structure. J. Dent. 33, 509-516.

Vallittu, P.K., 1994. Acrylic resin-fiber composite-part II: The effect of polymerization shrinkage of polymethyl methacrylate applied to fiber roving on transverse strength. J. Prosthet. Dent. 71, 613-617.

Vallittu, P.K., 1995. Impregnation of glass-fibers with polymethylmethacrylate using a powder-coating method. Appl. Compos. Mater. 2, 51-58.

Vallittu, P.K., 1996. A review of fiber-reinforced denture base resins. J. Prosthodont. $5,270-276$.

Vallittu, P.K., 1998. The effect of glass-fiber reinforcement on the fracture resitance of a provisional fixed-partial-denture. J. Prosthet. Dent. 79,125-130.

Vallittu, P.K., 1999. Prosthodontic treatment with a glass-fiber-reinforced resinbonded fixed-partial-denture: A clinical report. J. Prosthet. Dent. 82, 132-135.

Vallittu, P.K., Könönen, M., 2000. Biomechanical aspects and material properties. In: Karlsson, S., Nilner, K., Dahl, B., editors. A textbook of fixed prosthodontics: the Scandinavian approach. Stockholm: Gothia; p. 116-130.

Vallittu, P.K., Sevelius, C., 2000. Resin-bonded, glass-fiber-reinforced composite fixed-partial-dentures: A clinical study. J. Prosthet. Dent. 84, 413-418.

van Heumen, C.C., Tanner, J., van Dijken, J.W., Pikaar, R., Lassila, L.V., Creugers, N.H., Vallittu, P.K., Kreulen, C.M., 2010. Five-year survival of 3-unit fiber-reinforced composite fixed partial dentures in the posterior area. Dent. Mater. 26, 954-960.

Waki, T., Nakamura. T., Nakamura, T., Kinuta, S., Wakabayashi, K., Yatani. H., 2006. Fracture resistance of inlay-retained fixed partial dentures reinforced with 
fiber-reinforced composite. Dent. Mater. J. 25, 1-6.

Wyatt, C.C., 2007. Resin-bonded fixed partial dentures: what's new? J. Can. Dent. Assoc. 73, 933-938.

Yamaga, T., Sato, Y., Akagawa, Y., Taira, M., Wakasa, K., Yamaki, M., 1995. Hardness and fracture toughness of four commercial visible light-cured composite resin veneering materials. J. Oral. Rehabil. 22, 857-863.

Zhang, M., Matinlinna, J.P., 2011. E-glass fiber reinforced composites in dental applications. Silicon. DOI 10.1007/s12633-011-9075-x. 


\section{Captions to the legends and tables}

\section{Tables}

Table 1. The brands, codes, chemical compositions and manufacturers of the materials investigated in this study.

Table 2. The incidence and failure types per experimental group. Type 1: Cohesive fracture in the veneering resin without fiber exposure at either lingual or buccal site; Type 2: Cohesive fracture in the veneering resin without fiber exposure at both lingual and buccal site; Type 3: Cohesive veneering resin fracture including both lingual and buccal sites with fiber exposure; Type 4: Catastrophic pontic fracture where the inlay parts remained intact but the pontic itself splitted and Type 5: Small cracklines in the veneering resin with no obvious fracture of the pontic. See Table 1 for group abbreviations.

\section{Figures:}

Fig. 1 The view of the premolar and molar abutment teeth embedded in PMMA with $7 \mathrm{~mm}$ distance having standard box preparations.

Fig. 2 Conditioning of the cementation surface of the inlay parts of the FDP using chairside silica coating.

Fig. 3 Cementation of the inlay-retained FDP under oscillating vibrations.

Fig. 4 Mean of fracture strength values and standard deviations of the experimental groups. See Table 1 for group abbreviations.

Fig. 5 Typical view of Type 1 failure type: Cohesive fracture in the veneering resin without fiber exposure at the lingual site. 